\title{
Correlation of Augmented IL-8 Production to Premature Chronic Lung Disease: Implication of Posttranscriptional Regulation
}

\author{
HSIN-CHUN HUANG, FANG-YU TAI, FENG-SHENG WANG, CHIEH-AN LIU, TE-YAO HSU, \\ CHIA-YO OU, AND KUENDER D. YANG \\ Departments of Pediatrics [H.-C.H., F.-Y.T., F.-S.W., C.-A.L., K.D.Y.] and Obstetrics [T.-Y.H., C.-Y.O.], \\ Chang-Gung Memorial Hospital and Graduate Institute of Clinical Medical Science, Chang Gung \\ University at Kaohsiung, Kaohsiung 833, Taiwan
}

\begin{abstract}
ABS
Despite that advances in neonatal medicine have significantly
reduced the early mortality of premature infants, a considerable
number of them are still prone to develop chronic lung disease
(CLD) later. To find a method of early prevention, we investi-
gated the efficacy of using certain early proinflammatory re-
sponses to predict the development of CLD. In the present study,
34 premature infants who required endotracheal intubation
within 4 h of birth were recruited for analysis of IL-8, IL-10, and
TNF- $\alpha$ levels in their bronchoalveolar lavage (BAL) fluid and
blood. It was found that level of IL- 8 but not TNF- $\alpha$ or IL-10 in
initial BAL fluid was significantly correlated to neutrophils in the
BAL and inversely correlated to the gestational age of prematu-
rity. Elevation of IL- 8 level in BAL on the first day of life was
correlated to the development of CLD. Further studies showed
that neonatal cord blood released significantly higher IL- 8 but
lower TNF- $\alpha$ levels after stimulation by endotoxin. The aug-
mented IL- 8 mRNA expression in cord blood was inhibited by
\end{abstract}
Premature neonates are known to be susceptible to respiratory distress syndrome (RDS) followed by chronic lung disease (CLD). Recent advances in neonatal intensive care and surfactant replacement therapy have significantly enhanced the survival rate of premature infants who have RDS (1). The risk for developing CLD, however, remains high among premature infants (2). Causes of chronic lung injuries in premature infants may include lung immaturity (3) and aberrant cytokine production $(4,5)$ and lung development $(3,6)$.

Premature infants with CLD can be distinguished from those without CLD in that the former experience an ongoing inflam-

Received July 8, 2003; accepted April 11, 2005.

Correspondence: Kuender D. Yang, M.D., Ph.D., Chang Gung Children's Hospital at Kaohsiung, Department of Medical Research (12F12L), No. 123, Ta-Pei Road, Niau-Sung Hsiang, Kaohsiung 833, Taiwan; e-mail: yangkd@adm.cgmh.org.tw.

This study was supported in part by Taiwan National Health Research Institute Grant NHRI-EX90-9026SP and Kaohsiung Chang Gung Memorial Hospital Grant CMRPG-83039.

DOI: 10.1203/01.PDR.0000175886.46201.D7 actinomycin $\mathrm{D}$ but enhanced by cycloheximide, suggesting that IL-8 production is controlled by de novo transcriptional induction as well as posttranscriptional up-regulation of IL- 8 by neonatal leukocytes, relating to the development of CLD. Thus, an appropriate modulation of initial IL-8 production in premature infants might be beneficial for the prevention of the development of CLD. (Pediatr Res 58: 216-221, 2005)

AB, adult blood
BAL, bronchoalveolar lavage
CB, cord blood
CLD, chronic lung disease
GA, gestational age
LPS, lipopolysaccharide
RDS, respiratory distress syndrome
TNF- $\alpha$, tumor necrosis factor- $\alpha$

matory process that includes leukocytes infiltration and production of proinflammatory cytokines $(7,8)$. Influx of leukocytes into the lung may occur after oxygen supplementation and mechanical ventilation (9). Although oxidative stress can up-regulate proinflammatory cytokines (10), it remains controversial whether certain cytokines are involved in the development of premature CLD $(11,12)$. In this study, we proposed that a prematurity-related alteration of cytokine production might be implicated in premature infants with CLD. We assessed IL-8, IL-10, and tumor necrosis factor- $\alpha$ (TNF- $\alpha$ ) levels in bronchoalveolar lavage (BAL) fluid and blood of intubated premature infants, which were obtained at the time of blood collection for the analysis of blood gas or biochemistry. Correlations of the initial cytokine level to the gestational age (GA) and to the development of CLD were assessed. We found that IL- 8 but not TNF- $\alpha$ or IL-10 levels was correlated to CLD in premature infants. In an attempt to find a better method for the prevention of CLD, we also performed studies to investigate whether differences exist in the IL-8 induction pattern 
between neonatal cord blood $(\mathrm{CB})$ and adult blood $(\mathrm{AB})$ leukocytes by the targeting of certain inflammatory cytokines.

\section{METHODS}

Patients. Premature neonates who were in our neonatal intensive care unit and required intubation were recruited into this study, after informed consents were obtained. Neonates whose mothers had experienced chorioamnionitis, defining by body temperature $>38^{\circ} \mathrm{C}$ with the presence of malodorous vaginal discharge or leukocytosis $\left(>15,000 / \mathrm{mm}^{3}\right)$ without any other identifiable focus of infection, were excluded from the study. This study was approved by the Institutional Review Board of Chang Gung Memorial Hospital. All patients studied were intubated within $4 \mathrm{~h}$ of life as a result of respiratory distress and underwent ventilation through a time-cycled pressure-limited ventilator, which was set according to the routine protocol of our neonatal intensive care unit. The duration of intubation, episode of maternal fever without the presence of malodorous vaginal discharge or leukocytosis, the administration of perinatal antibiotics and oxygen supplementation, and oxygen index (OI), calculated from mean airway pressure $\times$ fraction of inspired oxygen/arterial oxygen pressure, were analyzed. In the presence of clinical and radiographic evidence of RDS, bovine surfactant (Survanta, Abbott Laboratories, North Chicago, IL; $100 \mathrm{mg} / \mathrm{kg}$ ) was used within not more than $4 \mathrm{~h}$ after birth. CLD was diagnosed when premature infants were oxygen dependent after $36 \mathrm{wk}$ GA and their chest $\mathrm{X}$-rays demonstrated characteristic remolding of CLD (13).

Sample collection and cytokine determination. The collection of BAL fluid from premature infants was performed during routine endotracheal suctioning on days $1,2,4$, and 7 as the infants remained intubated. On the first day, BAL was collected at 30 min after initial intubation but before the administration of Survanta. A 6- or 8-French end-hole suction catheter connected to a syringe that contained $1 \mathrm{~mL} / \mathrm{kg}$ physiologic saline solution was inserted through the end porthole of the endotracheal tube until resistance was felt (14). The catheter then was withdrawn $1 \mathrm{~cm}$ before the instillation of saline fluid. A small amount of air was introduced to clear the dead space, and the BAL fluid was aspirated into a syringe (15); the instillation and aspiration procedure was repeated three times $(14,16)$. During this procedure, the oxygen saturation level was monitored by a pulse oximeter and kept at $90-95 \%$. BAL samples were kept on ice and sent to the laboratory immediately. Supernatants of BAL samples were separated by centrifugation $(1500 \times g$ for $3 \mathrm{~min})$. After the supernatants were filtered through a $0.45-\mu \mathrm{m}$ filter (Ministart, Sartorius, Germany), samples were aliquotted into Eppendorf tubes and stored at $-80^{\circ} \mathrm{C}$ until batch analysis. The cell pellets were subjected to estimation of total leukocyte counts on a hemocytometer, and the differential cells were obtained by cytocentrifuge preparation. Cells were stained by Diff-Quick, and their differentials were estimated by counting at least 300 cells on each stain. Total leukocyte and neutrophil counts were presented as cells $/ \mathrm{mL}$ and correlated to IL-8 concentrations $(\mathrm{pg} / \mathrm{mL})$.

Concentrations of IL-8, IL-10, and TNF- $\alpha$ in the BAL and blood samples were measured as previously described (17). The sensitivity of the ELISA kits ( $\mathrm{R} \&$ D Systems, Minneapolis, MN) is downward to $10 \mathrm{pg} / \mathrm{mL}$ for IL-8, 0.5 $\mathrm{pg} / \mathrm{mL}$ for IL-10, and $4.4 \mathrm{pg} / \mathrm{mL}$ for TNF- $\alpha$. To compare the difference of IL- 8 and TNF- $\alpha$ production between $\mathrm{CB}$ and $\mathrm{AB}$, we added endotoxin $(0.1 \mu \mathrm{g} / \mathrm{mL}$; Sigma Chemical Co., St. Louis, MO) into the $\mathrm{CB}$ and $\mathrm{AB}$ for 2 and $6 \mathrm{~h}$, respectively, to measure the IL- 8 production.

Differentiation of transcriptional and posttranscriptional regulation of IL-8 production in $\boldsymbol{C B}$. Human umbilical CB was collected from normal, full-term deliveries after informed consents were obtained from the parents. Adult peripheral blood was obtained from 20- to 36-y-old healthy adult volunteers. For differentiating transcriptional and posttranscriptional regulation of IL-8 production, each sample $(5 \mathrm{~mL})$ was collected in heparinized $10-\mathrm{U} / \mathrm{mL}$ tubes and challenged by endotoxin with or without actinomycin D $(5 \mu \mathrm{g} / \mathrm{mL})$ or cycloheximide $(1 \mathrm{mg} / \mathrm{mL})$. Supernatants from the reactions, with and without actinomycin D, were assessed for IL- 8 production. Blood leukocytes from reactions with and without cycloheximide underwent total RNA extraction by using Tri reagent that contained a monophasic solution of guanidine thiocyanate and phenol (Sigma Chemical Co.).

Detection of IL-8 mRNA expression by real-time reverse transcriptionPCR. Quantitative measurement of IL-8 mRNA expression in the blood leukocytes was performed by a Model 7700 quantitative PCR machine (Applied Biosystems, Perkin-Elmer, Foster City, CA) for 40 cycles using real-time Taqman technology as modified from our previously described study (18). The forward primer, the reverse primer, and the probe sequence for IL- 8 mRNA quantification were 5'-CCT GAT TTC TGC AGC TCT GTG T-3', 5'-CGC AGT GTG GTC CAC TCT CA-3', and 5'-FAM-CTC CAA ACC TTT CCA CCC CAA ATT TAT CA-TAMRA-3', respectively. In addition, glyceraldehyde-3-phosphate dehydrogenase mRNA expression was used as an internal control. The forward primer, reverse primer, and the probe sequence were
5'-GAA GGT GAA GGT CGG AGT-3', 5'-GAA GAT GGT GAT GGG ATT TC-3', and 5'-CCG ACT CTT GCC CTT CGA AC-3', respectively. Each reverse transcription-PCR cycle included (1) $2 \mathrm{~min}$ at $50^{\circ} \mathrm{C}$ for the RT process and (2) 40 cycles of $30 \mathrm{~min}$ at $60^{\circ} \mathrm{C}, 5 \mathrm{~min}$ at $95^{\circ} \mathrm{C}, 20 \mathrm{~s}$ at $94^{\circ} \mathrm{C}$, and $1 \mathrm{~min}$ at $60^{\circ} \mathrm{C}$. The reverse transcription-PCR products could be detected by a paired hybridization probe in which the reporter dye, FAM, was labeled on the 5 ' end and the quenching dye, TAMRA, was labeled on the 3 ' end (18).

Statistical analysis. Differences in cytokine level between premature infants with and without CLD and surfactant treatment were tested by Mann-Whitney $U$ test and Wilcoxon signed ranks test, respectively. Categorical variables were analyzed by $\chi^{2}$ test or means of Fisher exact test. Kendall's correlation coefficient was used to describe associations between variables, and multiple regression analysis was used to detect any relationships among the variables. Data from in vitro experiments were tested by $t$ tests. Data were presented as mean values \pm SEM. A $p<0.05$ was considered statistically significant.

\section{RESULTS}

Demographic data of premature infants studied. Thirty-six premature infants with GA between 24 and 36 wk were investigated. One patient with congenital anomalies and another with sepsis were excluded from this analysis. As shown in Table 1, 12 of these 34 patients developed CLD; they were born at GA $<33$ wk. Twenty-two of the 34 patients were in the non-CLD group, and 10 of the 22 non-CLD patients were of GA $<33$ wk. Patients with CLD revealed significantly younger GA $(27.58 \pm 0.50$ versus $32.50 \pm 0.46 \mathrm{wk})$, lower birth weight $(1069.2 \pm 64.2$ versus $2009.9 \pm 121.3 \mathrm{~g})$, and longer duration of intubation ( $21.00 \pm 8.00$ versus $4.18 \pm 1.16 \mathrm{~d})$ and oxygen requirement $(63.50 \pm 8.88$ versus $17.05 \pm 3.25 \mathrm{~d})$, as compared with the non-CLD group. In contrast, Apgar score, gender, cesarean-section rate, prolonged rupture of membrane for $>24 \mathrm{~h}$, perinatal antibiotics, prenatal steroid, surfactant treatment, and OI calculated from the first arterial blood gas analysis performed $\sim 30$ min after initiation of mechanical ventilation were insignificantly different between both groups (Table 1). In addition, the first complete blood count assessed 30 min after birth was insignificantly different between both groups.

Changes of $I L-8$ concentration in BAL from premature infants. IL-8 levels in the BAL of premature infants assessed on the first day were inversely correlated to GA $(r=-0.332$,

Table 1. Demographic data of subjects studied

\begin{tabular}{lcc}
\hline \multicolumn{1}{c}{ Characteristics } & CLD $(n=12)$ & Non-CLD $(n=22)$ \\
\hline Gestational age (weeks) & $27.58 \pm 0.50$ & $32.50 \pm 0.46^{*}$ \\
Birth weight $(\mathrm{g})$ & $1069.2 \pm 64.2$ & $2009.9 \pm 121.3^{*}$ \\
Male & 7 & 15 \\
1-min Apgar & $3.92 \pm 0.65$ & $4.95 \pm 0.49$ \\
5-min Apgar & $6.67 \pm 0.69$ & $7.18 \pm 0.36$ \\
PROM $\geqq 24$ hrs & 2 & 6 \\
Perinatal antibiotics & 10 & 16 \\
Prenatal steroid & 3 & 3 \\
Maternal fever $\dagger$ & 3 & 7 \\
Cesaerean section & 6 & 15 \\
Surfactant treatment & 7 & 7 \\
OI (1 ${ }^{\text {st }}$ day) & $6.98 \pm 1.77$ & $8.03 \pm 1.63$ \\
Intubation duration (d) & $21.00 \pm 8.00$ & $4.18 \pm 1.16^{*}$ \\
$\mathrm{O}_{2}$ supplementation (d) & $63.50 \pm 8.88$ & $17.05 \pm 3.25^{*}$ \\
\hline
\end{tabular}

Maternal fever $\uparrow$ included subjects with simple maternal fever without malodorous vaginal discharge or leukocytosis.

CLD, chronic lung disease; PROM, prolonged rupture of membrane; OI, oxygen index $\left(\mathrm{MAP} \times \mathrm{FiO}_{2} / \mathrm{PaO}_{2}\right)$; d, days.

* Indicated the $p<0.05$ (Mann-Whitney $\mathrm{U}$ test). 
$p=0.008, n=34$ ) (Fig. 1). In contrast, levels of TNF- $\alpha$ in BAL $(r=-0.316, p=0.124, n=34)$ and IL-10 $(r=-0.241$, $p=0.407, n=34$ ) were not correlated to GA. IL-8 levels in initial BAL were significantly higher in CLD patients, compared with those $(\mathrm{GA}<33 \mathrm{wk})$ without the disease $(445.9 \pm$ 79.9 versus $83.2 \pm 32.0 \mathrm{pg} / \mathrm{mL} ; p=0.002$; Fig. $2 A)$. In contrast, levels of TNF- $\alpha(79.12 \pm 24.35$ versus $46.60 \pm 2.08$ $\mathrm{pg} / \mathrm{mL} ; p=0.230)$ or IL-10 (11.69 \pm 6.50 versus $3.77 \pm 2.02$ $\mathrm{pg} / \mathrm{mL} ; p=0.274$ ) in BAL that was obtained from premature infants with CLD were not significantly different from those without the disease. Level of IL-8 in BAL that was obtained from premature infants with CLD was increased progressively as they remained intubated for up to $7 \mathrm{~d}$ (Fig. $2 B$ ). In BAL, the level of IL-8 was significantly correlated to neutrophil count $(r$ $=0.786, p=0.021)$ rather than total leukocyte count $(p=$ $0.205)$. For those with surfactant treatment, there was no difference in BAL IL-8 level before (day 1) and after (day 2) surfactant therapy compared with those who had not received surfactant treatment. The recovered percentage of BAL fluid obtained from BAL of neonates with GA $<33$ wk was not significantly different between CLD and non-CLD groups $(58.38 \pm 6.02$ versus $57.90 \pm 3.15 \%)$.

Changes of IL-8 concentration in blood. To confirm that the augmented IL- 8 production in BAL was related to leukocyte responses, we collected $0.5 \mathrm{~mL}$ of blood at days 1,7 , and 21 during the blood gas analysis or biochemistry measurements from these premature infants $(\mathrm{GA}<33 \mathrm{wk})$ for the detection of IL- 8 and TNF- $\alpha$ levels in plasma. Premature infants with CLD seemed to have higher plasma IL-8 levels during their first 3 wk of life than those without CLD, but this increase was not significantly different between both groups (Fig. 3A). Plasma TNF- $\alpha$ level was lower in the CLD group initially, as compared with those without CLD (Fig. 3B). Because blood samples $(\leq 0.5 \mathrm{~mL})$ that we collected were suitable only for the measurement of two soluble cytokines, we collected normal CB subsequently to study the possible molecular mechanism of the augmented IL-8 production.

BAL

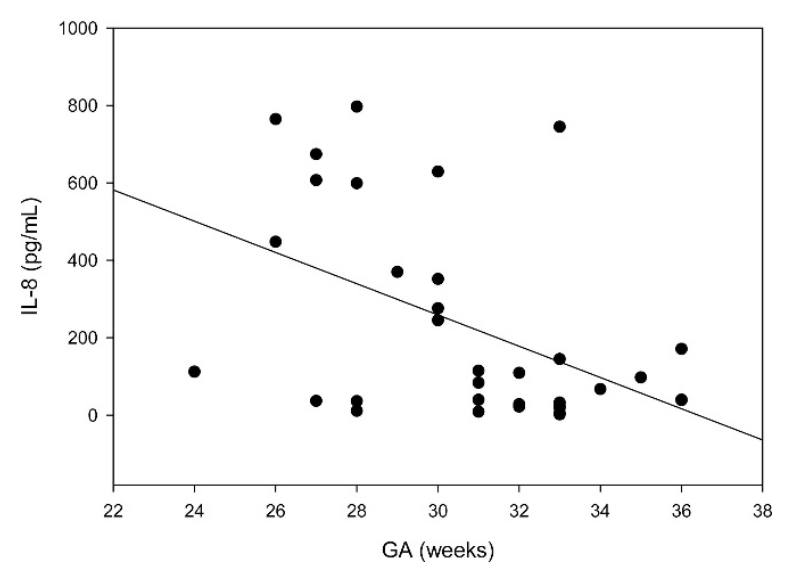

Figure 1. Correlation of IL-8 levels on the first day of BAL to GA. The first-day IL- 8 levels of BAL obtained from 34 premature infants were significantly correlated with their GA $(r=-0.332, p=0.008)$, as tested by Kendall's correlation.
(A)

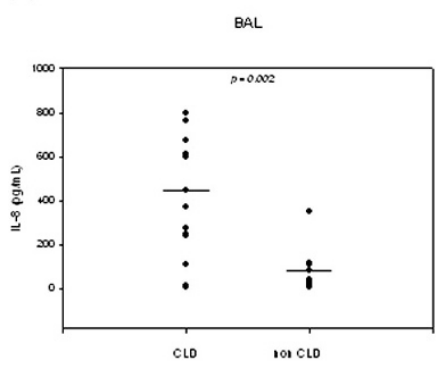

(B)

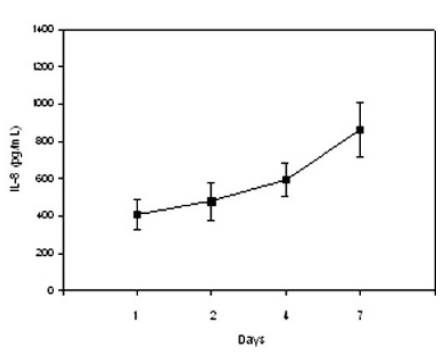

Figure 2. (A) Correlation of the initial BAL IL-8 levels to CLD. Premature infants (GA $<33$ wk) with CLD had significantly higher IL-8 levels on the first day of BAL than those (GA $<33$ wk) without CLD. Mean values are represented by solid lines. $(B)$ The IL-8 level in BAL obtained from premature infants who developed CLD revealed a progressive increase during their first week of life. Total patients studied were 34 premature infants. Twelve infants had GA $>33$ wk, and 12 and 10 infants $(\mathrm{GA}<33 \mathrm{wk})$ did and did not have CLD, respectively.

(A)

(B)
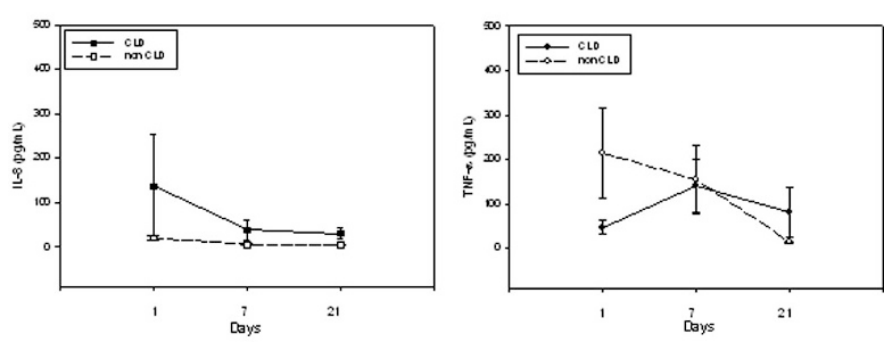

(C)

(D)
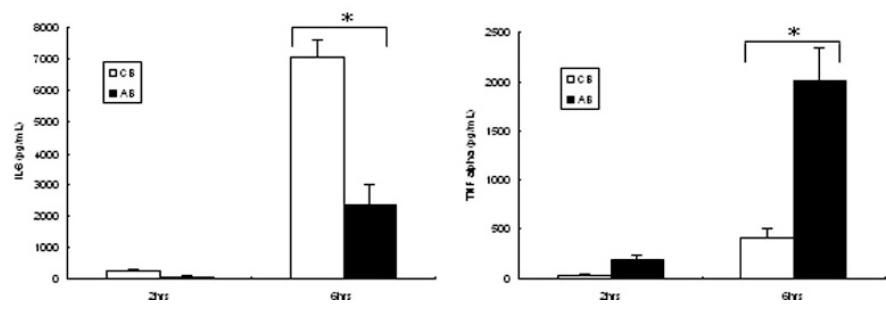

Figure 3. IL- 8 production in blood obtained from premature infants and normal CB. Plasma IL-8 $(A)$ and TNF- $\alpha(B)$ levels in premature infants with $(n=9)$ and without $(n=8)$ CLD. (C) IL-8 production in normal CB was significantly higher than those in $\mathrm{AB}$ after endotoxin (LPS, $0.1 \mu \mathrm{g} / \mathrm{mL}$ ) stimulation for 2 and $6 \mathrm{~h}$, respectively. $(D) \mathrm{TNF}-\alpha$ production in the $\mathrm{CB}$ was lower than that in $\mathrm{AB}$ after endotoxin (LPS, $0.1 \mu \mathrm{g} / \mathrm{mL}$ ) stimulation for 2 and $6 \mathrm{~h}$, respectively. Data regarding in vitro IL- 8 and TNF- $\alpha$ production by blood leukocytes were calculated from seven replicate experiments with paired $\mathrm{CB}$ and $\mathrm{AB}$ samples $(* p<0.001)$.

Differences of $I L-8$ and $T N F-\alpha$ production in $C B$ and $A B$ in response to endotoxin. IL- 8 level in neonatal $\mathrm{CB}$ was significantly higher in response to endotoxin (LPS, $0.1 \mu \mathrm{g} / \mathrm{mL}$ ) for $6 \mathrm{~h}$, compared with $\mathrm{AB}$ (Fig. 3C). In contrast, TNF- $\alpha$ production in neonatal $\mathrm{CB}$ was significantly lower in response to endotoxin, compared with $\mathrm{AB}$ (Fig. $3 D$ ). The results suggested that augmentation in IL-8 production in neonatal blood was not related to its upstream higher TNF- $\alpha$ production but might be more related to the prematurity-related alteration of IL-8 induction. 
Implication of posttranscriptional regulation of augmented IL-8 expression in CB leukocytes. To study why blood leukocytes in CB release a higher level of IL- 8 but not TNF- $\alpha$ than those in $\mathrm{AB}$, we used actinomycin $\mathrm{D}(5 \mu \mathrm{g} / \mathrm{mL})$ and cycloheximide $(1 \mathrm{mg} / \mathrm{mL})$ to explore whether the increase in IL-8 production was related to transcriptional or posttranscriptional regulation. The results showed that actinomycin D, which was added at $2 \mathrm{~h}$ after endotoxin (LPS) stimulation of blood leukocytes, almost inhibited the endotoxin-induced IL-8 production completely in $4 \mathrm{~h}$ in $\mathrm{CB}$ and $\mathrm{AB}$ (Fig. 4), indicating that endotoxin-mediated IL-8 production was related to de novo transcriptional induction after stimulation. The addition of cycloheximide at $2 \mathrm{~h}$ after endotoxin induction of IL-8 mRNA expression augmented IL-8 mRNA expression in CB (Fig. 5A-C) and $\mathrm{AB}$ leukocytes (Fig. 5D) in 4 h. Cycloheximide, which blocked all new protein synthesis, enhanced the IL-8 mRNA expression induced by LPS, suggesting that a repressor protein was responsible for posttranscriptional degradation of IL-8 mRNA expression. The cycloheximideaugmented IL-8 mRNA induction in CB leukocytes was higher than those of $\mathrm{AB}$, indicating that the posttranscriptional repressor protein was more fragile in $\mathrm{CB}$ leukocytes.

\section{DISCUSSION}

It has been proposed that CLD is mediated by higher proinflammatory cytokines (IL-6, TNF- $\alpha$, and IL-8) in conjunction with a lower anti-inflammatory (IL-10) cytokine arising from proinflammatory response $(7,8,19,20)$. It remains unclear which cytokine is actually involved in the development of CLD. Lyon $e t$ al. (21) showed that IL- $1 \beta$, TNF- $\alpha$, or IL-8 was not associated with CLD. Similarly, Kazzi et al. (11) failed to find an association in IL-1 $\beta$ or IL- 6 concentrations between tracheal aspirates and blood of premature infants who were at risk for developing CLD. Bagchi et al. (12) indicated that IL-6 bioactivity rather than TNF- $\alpha$ or IL- 6 concentration was associated with CLD in premature infants. In addition, BAL fluid obtained from premature neonates exhibits free elastase activity (22), which may degrade certain proteins, including TNF- $\alpha$. In this study, we found that IL-10 level did not decline and TNF- $\alpha$ level did not increase in

(A)

(B)
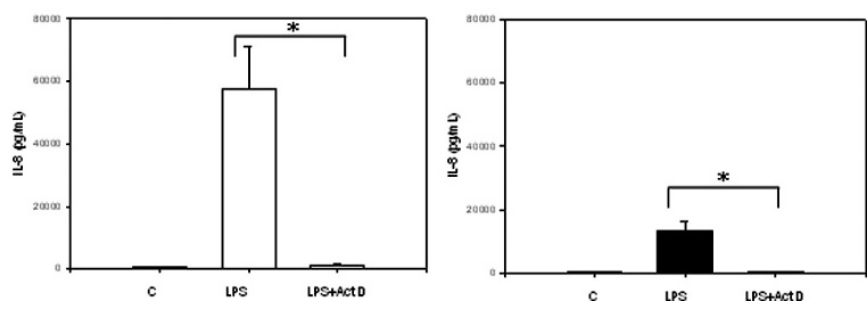

Figure 4. Actinomycin D (Act D) suppression of endotoxin-induced IL-8 production. Supernatants from endotoxin (LPS, $0.1 \mu \mathrm{g} / \mathrm{mL}$ ) stimulation of CB $(A)$ and $\mathrm{AB}(B)$ in the presence and absence of actinomycin $\mathrm{D}(5 \mu \mathrm{g} / \mathrm{mL})$ were subjected to measurement of IL- 8 concentrations. Act D almost completely inhibited the IL-8 production by endotoxin-induced IL-8 production in CB and $A B$. Data presented were calculated from five replicate experiments with paired $\mathrm{CB}$ and $\mathrm{AB}$ samples $(* p<0.001)$. "C" in the $x$ axis indicates the IL-8 production from the control reactions without stimulation.
(A)
IL-8 mRNA

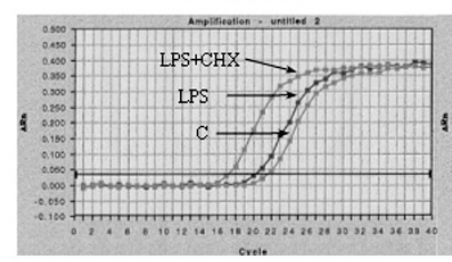

(C)

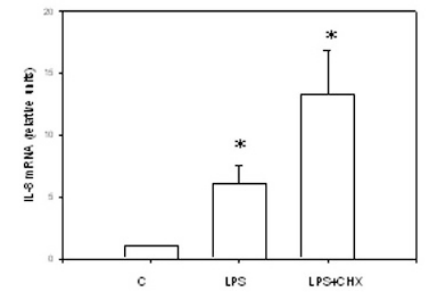

(B)

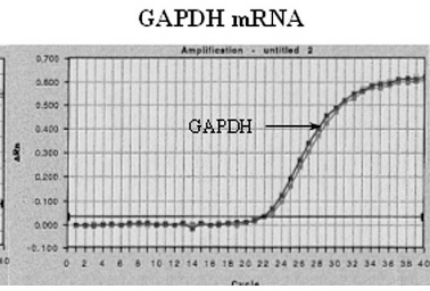

(D)

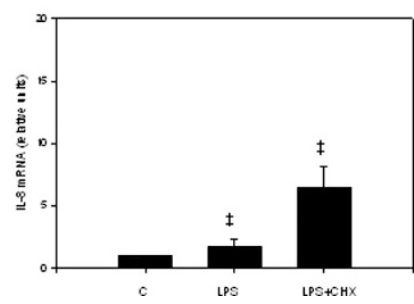

Figure 5. Quantitative analysis of IL-8 mRNA and glyceraldehyde-3phosphate dehydrogenase (GAPDH) mRNA expression in $\mathrm{CB}$ and $\mathrm{AB}$ leukocytes. In a representative experiment, we found that cycloheximide (CHX; 1 $\mu \mathrm{g} / \mathrm{mL})$ added to reaction $2 \mathrm{~h}$ after LPS $(0.1 \mu \mathrm{g} / \mathrm{mL})$ stimulation augmented the LPS-induced IL-8 mRNA expression in $4 \mathrm{~h}(A)$, in comparison with the internal control GAPDH mRNA expression $(B)$. A summary from seven replicate experiments with paired $\mathrm{CB}(C)$ and $\mathrm{AB}(D)$ leukocytes showed that CHX did significantly augment IL-8 mRNA induction $(* p=0.037 ; \ddagger p=$ 0.048).

premature infants with CLD, suggesting that increases in TNF- $\alpha$ and IL-1 $\beta$ level or decline in IL-10 level was not associated with the development of CLD.

Munshi et al. (8) demonstrated an increase in IL-8 level before the influx of leukocytes in BAL obtained from preterm infants with CLD. In recognition of the importance of early IL-8 induction in the development of premature CLD, we found that IL-8 level in BAL obtained on the first day was inversely correlated with prematurity (GA) and also associated with the development of CLD. If the cutoff value of the first-day BAL IL-8 concentration were set as 110 $\mathrm{pg} / \mathrm{mL}$, then it could be used to predict CLD with a sensitivity of $83 \%$ and a specificity of $73 \%$. The positive predictive value was $63 \%$, and the negative predictive value was $89 \%$. The finding that premature neonates demonstrated an augmented IL-8 production was different from a previous report showing that leukocytes of newborns, especially those of premature neonates, released less IL-8 (23). We also noticed that IL-8 level in BAL was in parallel with polymorphonuclear leukocyte influx in lavage fluid, as reported by other studies $(22,24)$. Chemokines, including IL-8, are implicated in the infiltration of leukocytes into the lungs $(25,26)$. We further noticed that IL-8 level in BAL increased with the duration of intubation. This was not related to TNF- $\alpha$ or IL-10 production, as they did not change with the duration of intubation. In BAL, a decline in IL-10 level was implicated in the augmentation of IL-6 and IL-8 production (7), although this study and other reports $(24,27)$ could not reproduce this result. Many previous studies collected BAL from days to weeks after birth, and this might introduce the confounding effects arising from acquired infection and different modes for the setting of 
fraction of inspired oxygen and ventilator. In the present study, BAL fluid was collected within $4 \mathrm{~h}$ of life, which was an optimal period to explore the impact of prematurity on initial IL-8 production.

With an attempt to study the relationship between CLD and the immune reaction of premature infants rather than their mothers, we excluded neonates whose mothers had experienced chorioamnionitis, which was defined by the presence of fever and malodorous vaginal discharge or leukocytosis. Whether maternal chorioamnionitis was a risk factor for CLD remained unclear. Redline et al. (28) failed to demonstrate such association, but Ogunyemi et al. (29) showed the opposite.

It is interesting to find a higher IL- 8 but lower TNF- $\alpha$ production in $\mathrm{CB}$ under endotoxin stimulation. In this study, a whole-blood model without counting the differential leukocytes between $\mathrm{AB}$ and $\mathrm{CB}$ was used. The higher IL- 8 but lower TNF- $\alpha$ production in $\mathrm{CB}$ than $\mathrm{AB}$ is more likely related to the intrinsic alteration of $\mathrm{CB}$ leukocytes. This may be not related to higher leukocytes in $\mathrm{CB}$, because higher leukocytes should release both higher IL-8 and TNF- $\alpha$ levels after endotoxin stimulation. A previous study showed that leukocytes of neonates released less IL-8 (23), but Schultz et al. (30) showed an augmented IL-8 production by neonatal leukocytes. In contrast, certain studies reported lower TNF- $\alpha$ production by neonatal leukocytes $(31,32)$. In fact, IL- 6 and IL- 8 but not TNF- $\alpha$ increased significantly in CB from neonates who had early onset of sepsis $(33,34)$. Nevertheless, we cannot exclude the possibility that the elevation of IL-8 level in BAL is related not only to leukocytes but also to pulmonary epithelial/endothelial cells (35-37).

It is still not known why a higher IL-8 level is found on the first day of BAL obtained from preterm infants. It is unlikely that the augmented IL- 8 production is related to earlier TNF- $\alpha$ induction, because we have shown that TNF- $\alpha$ level in BAL of the first day is not correlated to GA or the development of CLD, and its level in serum is also not correlated to GA or postnatal insults, as described in another report (38). In fact, we have found that IL- 8 but not TNF- $\alpha$ or IL-10 level in initial BAL fluid is inversely correlated to GA and that the elevation of IL-8 level in BAL on the first day is correlated to CLD. In addition, we noticed that initial OI for both groups is not significantly different (Table 1), although all infants were intubated on the first day of life. This suggests that premature neonates have an altered IL- 8 response that may be caused by prematurity rather than ventilator-associated injury. Furthermore, we find that the IL- 8 production by neonatal leukocytes is controlled by de novo transcriptional induction as well as posttranscriptional up-regulation in the presence of LPS. Thus, early pharmacologic regulation of IL-8 induction may be beneficial in the modulation of inflammatory reactions in premature infants. However, it should be manipulated appropriately, because some studies have mentioned that a complete knockdown of IL-8 or IL-8 receptor gene expression has raised immunodeficiency or chronic inflammation $(39,40)$.

Acknowledgments. We thank the medical staff in the neonatal intensive care unit and delivery room of Chang Gung Children's Hospital at Kaohsiung for help in collecting BAL fluids and blood specimens. Also, thanks to Dr. Eng-Yen Huang for statistical advice.

\section{REFERENCES}

1. Suresh GK, Soll RF 2001 Current surfactant use in premature infants. Clin Perinatol 28:671-694

2. Stevenson DK, Wright LL, Lemons JA, Oh W, Korones SB, Papile LA, Bauer CR, Stoll BJ, Tyson JE, Shankaran S, Fanaroff AA, Donovan EF, Ehrenkranz RA, Verter J 1998 Very low birth weight outcomes of the National Institute of Child Health and Human Development Neonatal Research Network, January 1993 through December 1994. Am J Obstet Gynecol 179:1632-1639

3. Hislop AA 2001 Bronchopulmonary dysplasia: prenatal and postnatal influences. Pediatr Pulmonol 23:107-109

4. Pierce MR, Bancalari E 1995 The role of inflammation in the pathogenesis of bronchopulmonary dysplasia. Pediatr Pulmonol 19:371-378

5. Ozdemir A, Brown MA, Morgan WJ 1997 Markers and mediators of inflammation in neonatal lung disease. Pediatr Pulmonol 23:292-306

6. Jobe AJ 1999 The new BPD: an arrest of lung development. Pediatr Res 46:641-643

7. Jones CA, Cayabyab RG, Kwong KY, Stotts C, Wong B, Hamdan H, Minoo P, deLemos RA 1996 Undetectable interleukin (IL)-10 and persistent IL-8 expression early in hyaline membrane disease: a possible developmental basis for the predisposition to chronic lung inflammation in preterm newborns. Pediatr Res 39:966-975

8. Munshi UK, Niu JO, Siddiq MM, Parton LA 1997 Elevation of interleukin-8 and interleukin-6 precedes the influx of neutrophils in tracheal aspirates from preterm infants who develop bronchopulmonary dysplasia. Pediatr Pulmonol 24:331-336

9. Zimmerman JJ 1995 Bronchoalveolar inflammatory pathophysiology of bronchopulmonary dysplasia. Clin Perinatol 22:429-456

10. Verhasselt V, Goldman M, Willems F 1998 Oxidative stress up-regulates IL-8 and TNF-alpha synthesis by human dendritic cells. Eur J Immunol 28:3886-3890

11. Kazzi SN, Romero R, McLaughlin K, Ager J, Janisse J 2001 Serial changes in level of IL-6 and IL- $1 \beta$ in premature infants at risk for bronchopulmonary dysplasia. Pediatr Pulmonol 31:220-226

12. Bagchi A, Viscardi RM, Taciak V, Ensor JE, McCrea KA, Hasday JD 1994 Increased activity of interleukin- 6 but not tumor necrosis factor- $\alpha$ in lung lavage of premature infants is associated with the development of bronchopulmonary dysplasia. Pediatr Res 36:244-252

13. Northway WH Jr, Rosan RC, Porter DY 1967 Pulmonary disease following respiratory therapy of hyaline membrane disease. Bronchopulmonary dysplasia. N Engl J Med 267:357-368

14. Ratjen F, Bruch J 1996 Adjustment of bronchoalveolar lavage volume to body weight in children. Pediatr Pulmonol 21:184-188

15. Schindler MB, Cox PN 1994 A simple method of bronchoalveolar lavage. Anaesth Intensive Care 22:66-68

16. Dargaville PA, South M, McDougall PN 1999 Comparison of two methods of diagnostic lung lavage in ventilated infants with lung disease. Am J Respir Crit Care Med 160:771-777

17. Yang KD, Shaio MF, Wang CL, Wu NC, Stone RM 1994 Neuroblastoma cellmediated leukocyte chemotaxis: lineage-specific differentiation of interleukin- 8 expression. Exp Cell Res 211:1-5

18. Wang CL, Wu YT, Lee CJ, Liu HC, Huang LT, Yang KD 2002 Decreased nitric oxide production after intravenous immunoglobulin treatment in patients with Kawasaki disease. J Pediatr 141:560-565

19. De Dooy JJ, Mahieu LM, Van Bever HP 2001 The role of inflammation in the development of chronic lung disease in neonates. Eur J Pediatr 160:457-463

20. Jonsson B, Tullus K, Brauner A, Lu Y, Noack G 1997 Early increase of TNF alpha and IL-6 in tracheobronchial aspirate fluid indicator of subsequent chronic lung disease in preterm infants. Arch Dis Child Fetal Neonatal Ed 77:F198-F201

21. Lyon AJ, McColm J, Middlemist L, Fergusson S, McIntosh N, Ross PW 1998 Randomized trial of erythromycin on the development of chronic lung disease in preterm infants. Arch Dis Child Fetal Neonatal Ed 78:F10-F14

22. Ogden BE, Murphy SA, Saunders GC, Pathak D, Johnson JD 1984 Neonatal lung neutrophils and elastase/proteinase inhibitor imbalance. Am Rev Respir Dis 130:817821

23. Schibler KR, Trautman MS, Liechty KW, White WL, Rothstein G, Christensen RD 1993 Diminished transcription of interleukin- 8 by monocytes from preterm neonates. J Leukoc Biol 53:399-403

24. McColm JR, Stenson BJ, Biermasz N, McIntosh N 2000 Measurement of interleukin 10 in bronchoalveolar lavage from preterm ventilated infants. Arch Dis Child Fetal Neonatal Ed 82:156-159

25. Merritt TA, Stuard ID, Puccia J, Wood B, Edwards DK, Finkelstein J, Shapiro DL 1981 Newborn tracheal aspirate cytology: classification during respiratory distress syndrome and bronchopulmonary dysplasia. J Pediatr 98:949-956

26. Strieter RM, Lukacs NW, Standiford TJ, Kunkel SL 1993 Cytokines and lung inflammation: mechanisms of neutrophil recruitment to the lung. Thorax 48:765-769

27. Beresford MW, Shaw NJ 2002 Detectable IL-8 and IL-10 in bronchoalveolar lavage fluid from preterm infants ventilated for respiratory distress syndrome. Pediatr Res 52:973-978

28. Redline RW, Wilson-Costello D, Hack M 2002 Placental and other perinatal risk factors for chronic lung disease in very low birth weight infants. Pediatr Res 52:713-719 
29. Ogunyemi D, Murillo M, Jackson U, Hunter N, Alperson B 2003 The relationship between placental histopathology findings and perinatal outcome in preterm infants. J Matern Fetal Neonatal Med 13:102-109

30. Schultz C, Rott C, Temming P, Schlenke P, Moller JC, Bucsky P 2002 Enhanced interleukin-6 and interleukin-8 synthesis in term and preterm infants. Pediatr Res $51: 317-322$

31. Serushago B, Issekutz AC, Lee SH, Rajaraman K, Bortolussi R 1996 Deficient tumor necrosis factor secretion by cord blood mononuclear cells upon in vitro stimulation with Listeria monocytogenes. J Interferon Cytokine Res 16:381-387

32. Liu E, Tu W, Law HK, Lau YL 2001 Changes of CD14 and CD1a expression in response to IL-4 and granulocyte-macrophage colony-stimulating factor are different in cord blood and adult blood monocytes. Pediatr Res 50:184-189

33. Santana C, Guindeo MC, Gonzalez G, Garcia-Munoz F, Saavedra P, Domenech E 2001 Cord blood levels of cytokines as predictors of early neonatal sepsis. Acta Paediatr 90:1176-1181

34. Kashlan F, Smulian J, Shen-Schwarz S, Anwar M, Hiatt M, Hegyi T 2000 Umbilical vein interleukin 6 and tumor necrosis factor alpha plasma concentrations in the very preterm infant. Pediatr Infect Dis J 19:238-243

35. Standiford TJ, Kunkel SL, Basha MA, Chensue SW, Lynch JP 3rd, Toews GB, Westwick J, Strieter RM 1990 Interleukin-8 gene expression by a pulmonary epithelial cell line. A model for cytokine networks in the lung. J Clin Invest 86:1945-1953

36. Walsh DE, Greene CM, Carroll TP, Taggart CC, Gallagher PM, O'Neill SJ, McElvaney NG 2001 Interleukin-8 up-regulation by neutrophil elastase is mediated by MyD88/IRAK/TRAF-6 in human bronchial epithelium. J Biol Chem 276:35494-35499

37. Lakshminarayanan V, Drab-Weiss EA, Roebuck KA $1998 \mathrm{H}_{2} \mathrm{O}_{2}$ and tumor necrosis factor- $\alpha$ induce differential binding of the redox-responsive transcription factors AP-1 and NF- $\kappa \mathrm{B}$ to the interleukin- 8 promoter in endothelial and epithelial cells. J Biol Chem 273:32670-32678

38. Atici A, Satar M, Cetiner S, Yaman A 1997 Serum tumor necrosis factor-alpha in neonatal sepsis. Am J Perinatol 14:401-404

39. Godaly G, Bergsten G, Hang L, Fischer H, Frendeus B, Lundstedt AC, Samuelsson M, Samuelsson P, Svanborg C 2001 Neutrophil recruitment, chemokine receptors, and resistance to mucosal infection. J Leukoc Biol 69:899-906

40. Czuprynski CJ, Brown JF, Steinberg H, Carroll D 1998 Mice lacking the murine interleukin- 8 receptor homologue demonstrate paradoxical responses to acute and chronic experimental infection with Listeria monocytogenes. Microb Pathog $24: 17-23$ 